\title{
Original Article (short paper) \\ Waist circumference percentile in children from municipalities of developed and developing countries
}

\author{
Alynne Christian Ribeiro Andaki ${ }^{1,3 *}$, Edmar Lacerda Mendes ${ }^{1,3}$, Adelson Luiz Araújo Tinoco ${ }^{2}$, Amanda Santos ${ }^{3}$, Bru- \\ no Sousa ${ }^{4}$, Susana Vale ${ }^{3,5}$, Jorge Mota ${ }^{3}$ \\ ${ }^{1}$ Universidade Federal do Triângulo Mineiro,UFTM, Uberaba, MG, Brazil; ${ }^{2}$ Universidade Federal de Viçosa,UFV, \\ Viçosa, MG, Brazil, ${ }^{3}$ CIAFEL-LAB, Universidade do Porto, Porto, Portugal; ${ }^{4}$ Universidade Lusófona de \\ Humanidades e Tecnologias, CBIOS, Portugal; ${ }^{5}$ Instituto Politénico do Porto, Porto, Portugal.
}

\begin{abstract}
Aims: to design reference percentile curves of waist circumference (WC) in children aged 6-10 from municipalities of developed (Portugal) and developing (Brazil) countries and to compare these results with other international references. Methods: this cross-sectional study enrolled a 6-10-year-old probability sampling. Univariate analysis of covariance adjusted by height was carried out to test the main effects of age, sex, countries, and interactions. WC percentile curves were performed with the LMS Chart Maker. Results: The sample comprised 6,475 children. Portuguese children presented a curvilinear increase in WC curves and Brazilian WC curves have shown a linear increase with age both for boys and girls. Overweight and obesity prevalence was $15.9 \%$ and $4.7 \%$ for Portuguese children and $12.9 \% 4.5 \%$ for Brazilian children, respectively. There was a main effect $(\mathrm{p}<0.0001)$ for age and countries, and an interaction effect for sex*age $(\mathrm{p}=0.001)$ and countries*age $(\mathrm{p}<0.0001)$. Portuguese boys and girls have shown higher values for the 50th, 75th, and 95th percentiles than Brazilian boys and girls. Conclusions: WC reference percentile curves were drawn for 6-10-year-old Portuguese and Brazilian children. Portuguese children have higher WC values than Brazilian children and other children from developed countries.
\end{abstract}

Keywords: abdominal obesity. child. reference values. anthropometry. methods.

\section{Introduction}

An obesity epidemic affects developed ${ }^{1}$ and developing countries ${ }^{2,3}$. The paradox between obesity and poverty has been discussing the obesity rate growth in developed countries, especially in poor areas ${ }^{1}$. On the other hand, Olaya et al. ${ }^{4}$ showed that children in higher income countries (Western Europe) had lower risk of overweight and obesity. Political-economic transitions and socio-demographic changes in Eastern European countries might explain the increased risk of obesity. However, Wabitsh et al. ${ }^{5}$ pointed out an unexpected stabilization or reduction of childhood obesity rates in developed countries and suggested urgent public health programs in developing countries to minimize children's obesity rates, including increases in physical activity and decline in screen time and consumption of sugar-sweetened soft drinks.

Anthropometric measures have been widely used to quantify and classify the obesity status among children according to sex, age, and race-ethnicity.Waist circumference (WC) has been considered one of the most commonly used anthropometric index to define abdominal obesity ${ }^{6}$, to predict cardiovascular risk factors ${ }^{7}$ (CVRF), including hypertension ${ }^{6,8}$, abdominal aortic intima-media thickness ${ }^{9}$, elevated levels of HOMA-IR and fasting insulin ${ }^{10}$, and altered left ventricular diastolic function ${ }^{11}$. Thereby, abdominal obesity has also become a serious health problem in children and should be managed carefully ${ }^{6}$.
The development of reference values for anthropometric measures based on national data is necessary to monitor obesity over time at an individual and population level. In this sense, developed $^{12-14}$ and developing ${ }^{15-18}$ countries have established WC percentile reference curves for their children. Portuguese and Brazilian 6-10-year-old children do not have a percentile curves with normative parameters according to the national and international comparisons. Reference curves are an important public healthy tool to the early identification of possible risk of abdominal obesity. Moreover, some studies have showed changes in the children's adiposity over time. Freedman et al. ${ }^{19}$ observed that the secular increases in WC among boys $(3.7 \mathrm{~cm})$ and girls $(6$ $\mathrm{cm}$ ) from 1988-1994 compared to 2011-2012 reduced about 75\% for boys and $50 \%$ for girls after BMI adjustment. Other studies revealed that there was no BMI increase after WC increases over time ${ }^{20,21}$,suggesting that BMI might be a less sensitive tool to detect changes in the children's central obesity. This methodological approach is key for the government's decision making regarding prevention and control in childhood obesity.

In summary, there is need to develop reference values and comparisons between the data from different countries to update the information on abdominal obesity proportion in children and establish consistent trends in developed and developing countries. Therefore, this study aims (a) to design reference 
percentile curves of waist circumference in 6-10-year-old children from municipalities of developed (Portugal) and developing (Brazil) countries; and (b) to compare these results with other international references.

\section{Methods}

\section{Study design}

This cross-sectional study used a 6-10-year-old sampling from Portugal and Brazil. Portuguese data were collected in the metropolitan area of Porto, in the North of Portugal (10 schools), and the Autonomous Region of Madeira (50 schools). In Brazil, data were collected in both Uberaba (15 schools) and Viçosa (8 schools), located in the South-Eastern region of the country. The required sample size was estimated based on the number of children enrolled in primary education of each city, prevalence of $50 \%$ abdominal obesity (unknown prevalence in the municipality), tolerance error of $5 \%$, and a confidence level of $95 \%$. In the first stage, the eligible schools were randomly selected. In the second stage, the classrooms were selected and all children were invited and had the same chance to participate in this study.

\section{Procedures}

After approval by the Ethics Committee (CEP/UFTM 1710, CEP/UFV 095/2011), the schools' principals were contacted to obtain authorization and to schedule data collection. Students who met the inclusion criteria and were interested in participate in the study received an Informed Consent Statement for their parents' acknowledgement and signing. Anthropometric measurements were performed at the schools by following specific protocols.

\section{Anthropometry}

Body mass (BM) was obtained by digital electronic scale with a $150 \mathrm{~kg}$ maximum capacity and $100 \mathrm{~g}$ accuracy, the height $(\mathrm{H})$ was obtained using a portable stadiometer with a 2 meter length and a scale of $0.1 \mathrm{~cm}$, and the children were wearing light clothing and no shoes, according to the standard techniques ${ }^{22}$. Body mass index (BMI) was calculated by dividing body mass by squared height $(\mathrm{m})$. Children were classified as overweight and obese based on the International Obesity Task Force (IOTF) criteria ${ }^{23}$.

Waist circumference (WC) measurements were taken at midpoint between the iliac crest and the lower rib, after normal expiration using a flexible and non-elastic $2 \mathrm{~m}$ tape, as recommended by the World Health Organization ${ }^{24}$.

\section{Comparisons between countries}

The Word Bank method has been used to classify developed and developing countries (Gross National Income per capta $\geq$ US $\$ 12,736$ was considered developed country). A literature review was performed and data on the 50th and 75th WC percentiles was obtained for comparisons between countries. Comparison was limited to studies that had used the LMS methodology and the same WC benchmark. The following countries were considered developed (High Income): Chile ${ }^{25}$, Venezuela ${ }^{26}$, Germany ${ }^{13}$, Kwait ${ }^{27}$, Poland ${ }^{28}$, and Portugal. Brazil, Bulgaria $^{29}$, China ${ }^{30}$, Malaysia ${ }^{31}$, Thailand ${ }^{18}$, Turkey $^{15}$ and Peru ${ }^{17}$ were classified as developing countries (Upper Middle Income).

\section{Statistical analysis}

An univariate analysis of covariance (ANCOVA) was carried out to test the main effects of age (6 to 10 years old), sex (girls and boys), countries (Portugal and Brazil) and interactions (age*sex, age*countries, sex*countries and age* ${ }^{*}$ sex*countries). Height was entered as covariate. The effect size (ES) was calculated as recommended by Cohen ${ }^{32}$. The Chi-square test was performed to verify the association between the frequency of high waist circumference (WC $>75^{\text {th }}$ ) and countries. Statistical analyses were performed using the SPSS software version 21 for Windows (SPSS, Inc, Chicago, Illinois).

Waist circumference percentile curves were performed with the LMS Chart Maker Pro version 2.54 software $^{33}$. The LMS method assumes that data can be normalized by using power transformation. Percentile curves were designed to smooth specific age and sex curves: $\mathrm{L}$ for skewness, $\mathrm{M}$ for median and $\mathrm{S}$ for coefficient of variation. Further comparisons should hold 5 th, 10th, 25th, 50th, 75th, 90th and 95th percentiles as benchmarks ${ }^{34}$.

\section{Results}

The sample comprised 6,475 children, 4,052 from Portugal $(\mathrm{BM}=30.91 \pm 8.95 \mathrm{~kg} ; \mathrm{H}=1.29 \pm 0.10 \mathrm{~m} ; \mathrm{BMI}=18.05 \pm 3.22$ $\mathrm{kg} / \mathrm{m}^{2} ; 51.50 \%$ boys) and 2,423 from Brazil (BM= $30.95 \pm$ $9.13 \mathrm{~kg} ; \mathrm{H}=1.31 \pm 0.09 \mathrm{~m} ; \mathrm{BMI}=17.53 \pm 3.50 \mathrm{~kg} / \mathrm{m}^{2} ; 54.40 \%$ girls). Overweight and obesity prevalence was $15.9 \%$ and 4.7\% in Portuguese children and $12.9 \%$ and $4.5 \%$ in Brazilian children, respectively.

Waist circumference descriptive statistics is in Table 1. ANCOVA with $\mathrm{WC}$ as the dependent variable, height as covariate, and age, sex, and countries as fixed factors, showed significant effects for age $\left[\mathrm{F}_{(4.5604)}=4.639 ; \mathrm{p}<0.0001 ; \mathrm{ES}=0.006\right]$, countries $\left[\mathrm{F}_{(1,5604)}=1084.459 ; \mathrm{p}<0.0001 ; \mathrm{ES}=0.162\right]$, and interactions sex*age $\left[\mathrm{F}_{(4,5604)}=8.600 ; \mathrm{p}=0.001 ; \mathrm{ES}=0.003\right]$ and countries*age $\left[\mathrm{F}_{(4,5604)}=66.926 ; \mathrm{p}<0.0001 ; \mathrm{ES}=0.046\right]$. 
Table 1: Waist circumference in Portuguese and Brazilian children according to age and sex

\begin{tabular}{|c|c|c|c|c|c|c|c|c|c|c|}
\hline \multirow[b]{3}{*}{$\begin{array}{c}\text { Age } \\
\text { (years) }\end{array}$} & \multicolumn{8}{|c|}{ Waist circumference } & \multicolumn{2}{|c|}{ ANCOVA p-value } \\
\hline & \multicolumn{4}{|c|}{ Portugal $^{*}$} & \multicolumn{4}{|c|}{ Brazil $^{*}$} & sex*age & countries*age \\
\hline & $\mathbf{n}$ & Girls & $\mathbf{n}$ & Boys & $\mathbf{n}$ & Girls & $\mathbf{n}$ & Boys & \multirow{7}{*}{0.001} & \multirow{7}{*}{$<0.001$} \\
\hline 6 & 500 & $59.20 \pm 7.09$ & 476 & $58.94 \pm 6.90$ & 191 & $56.94 \pm 7.64$ & 166 & $56.47 \pm 7.00$ & & \\
\hline 7 & 405 & $61.11 \pm 7.86$ & 453 & $60.90 \pm 7.81$ & 276 & $59.19 \pm 8.36$ & 251 & $59.27 \pm 8.73$ & & \\
\hline 8 & 319 & $65.32 \pm 8.87$ & 364 & $64.00 \pm 8.94$ & 270 & $59.99 \pm 8.06$ & 210 & $60.09 \pm 8.41$ & & \\
\hline $9^{* *}$ & 400 & $67.31 \pm 9.23$ & 457 & $68.01 \pm 10.32$ & 292 & $61.57 \pm 8.97$ & 256 & $61.46 \pm 9.31$ & & \\
\hline $10^{* *}$ & 327 & $66.87 \pm 8.56$ & 351 & $68.62 \pm 10.33$ & 289 & $61.29 \pm 9.52$ & 222 & $62.79 \pm 9.73$ & & \\
\hline Total & 1951 & $63.55 \pm 8.92$ & 2101 & $63.83 \pm 9.67$ & 1318 & $60.01 \pm 8.73$ & 1105 & $60.22 \pm 8.99$ & & \\
\hline
\end{tabular}

Note: Adjusted by height; *difference between groups; **no difference between ages;

We developed and smoothed the sex and age-specific WC percentile values at the 5th, 10th, 25th, 50th, 75th, 90th and 95th percentiles of Portuguese (Table 2) and Brazilian (Table 3) by the LMS method, Figure 1. The Portuguese children presented a curvilinear increase in WC curves and Brazilian WC curves have shown a linear increase in age both for boys and girls.

Table 2: Smoothed age-specific percentile values of waist circumference in Portuguese girls and boys

\begin{tabular}{|c|c|c|c|c|c|c|c|c|c|c|}
\hline \multirow{2}{*}{ Age (Years) } & \multirow[t]{2}{*}{$\mathbf{L}$} & \multirow[t]{2}{*}{$\mathbf{M}$} & \multirow[t]{2}{*}{$\mathbf{S}$} & \multicolumn{7}{|c|}{ WC percentile $(\mathrm{cm})$} \\
\hline & & & & 5 th & 10th & 25th & 50th & 75th & 90th & 95th \\
\hline \multicolumn{11}{|l|}{ Girls } \\
\hline 6 & -2.971 & 57.190 & 0.097 & 50.18 & 51.44 & 53.86 & 57.19 & 61.52 & 66.81 & 71.04 \\
\hline 7 & -2.504 & 58.992 & 0.109 & 50.87 & 52.33 & 55.14 & 58.99 & 63.99 & 70.07 & 74.86 \\
\hline 8 & -2.118 & 62.069 & 0.119 & 52.72 & 54.40 & 57.65 & 62.07 & 67.76 & 74.57 & 79.84 \\
\hline 9 & -1.798 & 65.003 & 0.123 & 54.72 & 56.59 & 60.17 & 65.00 & 71.10 & 78.20 & 83.54 \\
\hline 10 & -1.585 & 65.927 & 0.121 & 55.47 & 57.41 & 61.07 & 65.93 & 71.93 & 78.73 & 83.68 \\
\hline \multicolumn{11}{|l|}{ Boys } \\
\hline 6 & -3.348 & 57.086 & 0.097 & 50.25 & 51.46 & 53.81 & 57.09 & 61.45 & 67.01 & 71.67 \\
\hline 7 & -3.331 & 58.550 & 0.095 & 51.63 & 52.87 & 55.25 & 58.55 & 62.92 & 68.43 & 72.99 \\
\hline 8 & -3.256 & 60.905 & 0.103 & 53.20 & 54.56 & 57.20 & 60.90 & 65.91 & 72.42 & 77.99 \\
\hline 9 & -2.858 & 63.970 & 0.119 & 54.75 & 56.36 & 59.51 & 63.97 & 70.08 & 78.17 & 85.25 \\
\hline 10 & -2.492 & 66.672 & 0.126 & 56.38 & 58.19 & 61.71 & 66.67 & 73.38 & 82.05 & 89.38 \\
\hline
\end{tabular}

Table3: Smoothed age-specific percentile values of waist circumference in Brazilian girls and boys

\begin{tabular}{|c|c|c|c|c|c|c|c|c|c|c|}
\hline \multirow[t]{2}{*}{ Age (years) } & \multirow[t]{2}{*}{$\mathbf{L}$} & \multirow[t]{2}{*}{$\mathbf{M}$} & \multirow[t]{2}{*}{$\mathbf{S}$} & \multicolumn{7}{|c|}{ WC percentile (cm) } \\
\hline & & & & 5 th & 10th & 25th & 50th & 75th & 90th & 95th \\
\hline \multicolumn{11}{|l|}{ Girls } \\
\hline 6 & -3.007 & 56.161 & 0.107 & 48.74 & 50.05 & 52.60 & 56.16 & 60.94 & 67.07 & 72.24 \\
\hline 7 & -2.960 & 57.085 & 0.111 & 49.34 & 50.70 & 53.35 & 57.08 & 62.12 & 68.65 & 74.21 \\
\hline 8 & -2.859 & 57.424 & 0.114 & 49.41 & 50.82 & 53.57 & 57.42 & 62.64 & 69.39 & 75.15 \\
\hline 9 & -2.786 & 59.198 & 0.114 & 50.91 & 52.37 & 55.21 & 59.20 & 64.55 & 71.41 & 77.17 \\
\hline 10 & -2.715 & 59.714 & 0.117 & 51.13 & 52.64 & 55.58 & 59.71 & 65.28 & 72.45 & 78.50 \\
\hline \multicolumn{11}{|l|}{ Boys } \\
\hline 6 & -3.516 & 55.632 & 0.097 & 49.03 & 50.19 & 52.46 & 55.63 & 59.91 & 65.47 & 70.23 \\
\hline 7 & -3.752 & 56.393 & 0.104 & 49.44 & 50.64 & 53.00 & 56.39 & 61.15 & 67.76 & 73.98 \\
\hline 8 & -3.769 & 57.700 & 0.102 & 50.65 & 51.87 & 54.27 & 57.70 & 62.50 & 69.14 & 75.36 \\
\hline 9 & -3.480 & 58.705 & 0.108 & 51.14 & 52.45 & 55.02 & 58.70 & 63.83 & 70.85 & 77.31 \\
\hline 10 & -2.940 & 60.516 & 0.118 & 51.88 & 53.38 & 56.32 & 60.52 & 66.29 & 74.00 & 80.82 \\
\hline
\end{tabular}


Figure 1: Smoothed reference curves for the 5th, 10th, 25th, 50th, 75th, 90th and 95th percentiles of waist circumference in Portuguese and Brazilian girls and boys aged 6-10 years
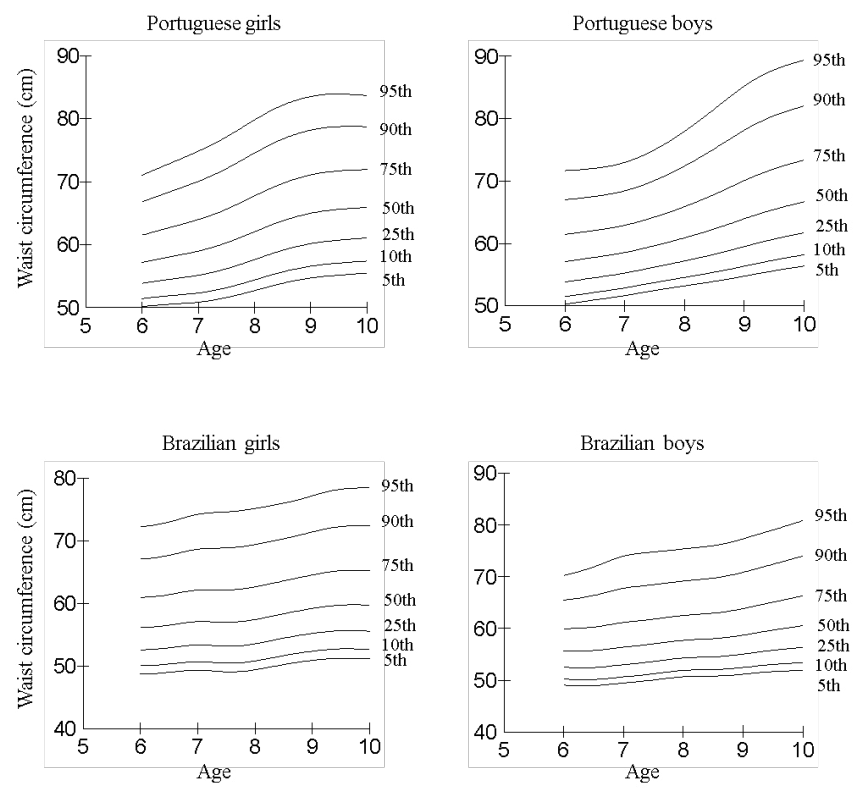

The comparisons of the age and sex-specific 50th and 75th WC percentiles between children from developed countries and Portugal, and Brazilian children and developing countries are in Figure 2. The frequency of WC $>75$ th was of $35.9 \%$ for Portuguese children and $22.9 \%$ for Brazilians, and there was a significant difference between countries $(\mathrm{p}<0.001$; Chi-square test). Chile showed the highest WC values in the 50th and 75th percentiles among developed countries and Polish children had the lowest WC values. Brazilian girls aged 6-8 showed the highest values for the 50th and 75th percentiles, while Chinese boys aged 8-10 showed the highest values for the 75 th percentile. Overall, Malaysia presented the lowest values for the 50th percentile of all ages and both sexes, as well as when compared to girls in the 75th percentile. The values for the 75th percentile in Malaysian boys were closer to Peruvian boys, which showed to be the lowest values. Portuguese boys and girls have been shown higher values for 50th, 75th, and 95th percentiles than Brazilian boys and girls (Figure 3 ).

Figure 2: Comparisons of age and sex in the 50th percentile (A) and 75th percentile (B) values of waist circumference between Portugal and other developed countries and Brazil and other developing countries.

A)

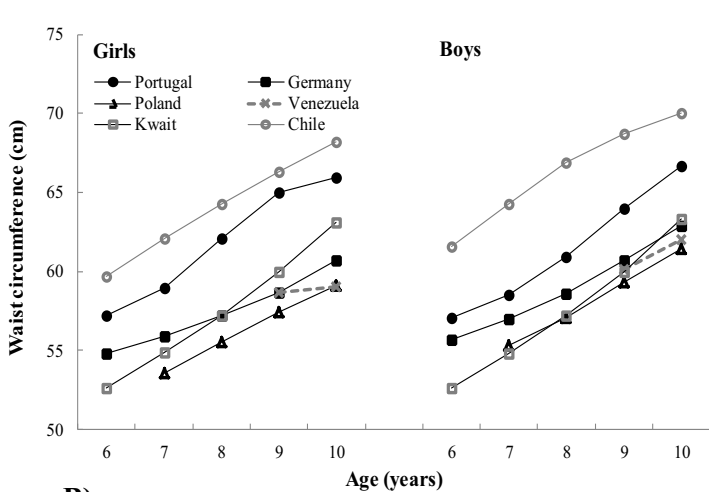

B)

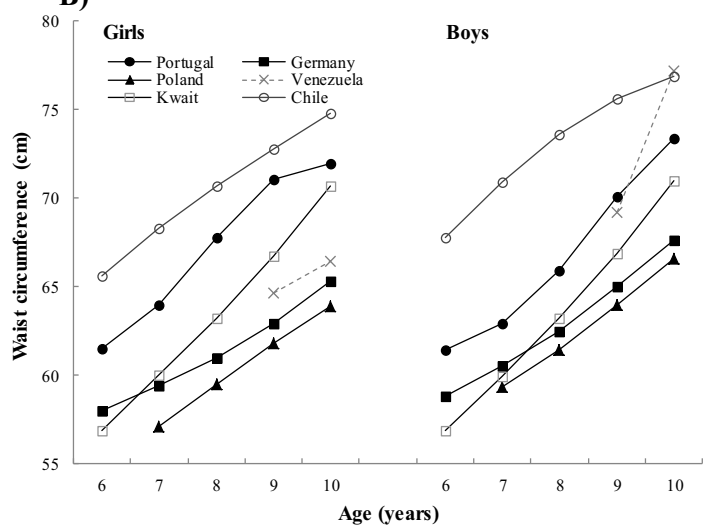

A)

Developing countries

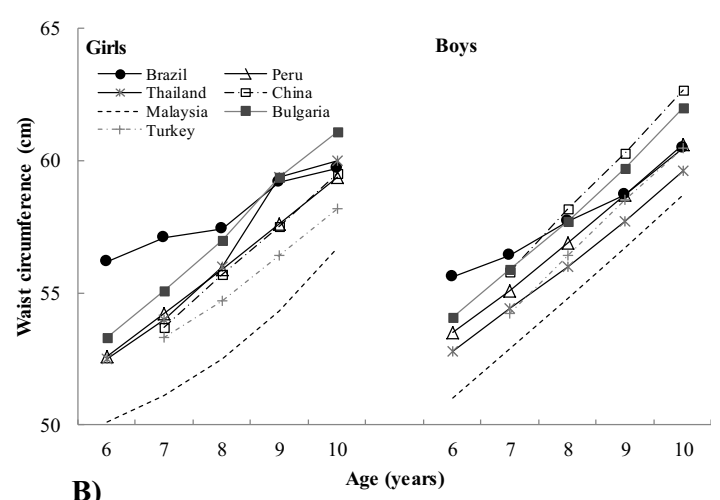

B)

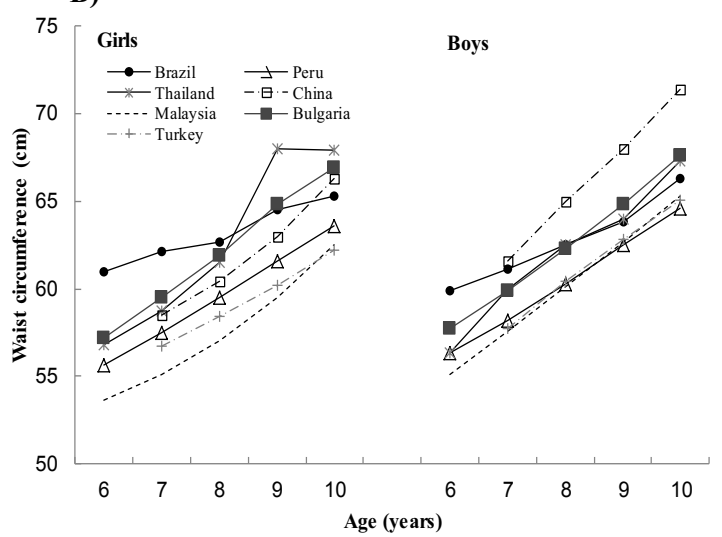


Figure 3: Comparisons of age and sex in the 50th, 75th and 95th percentiles for waist circumference of Portuguese and Brazilian children.

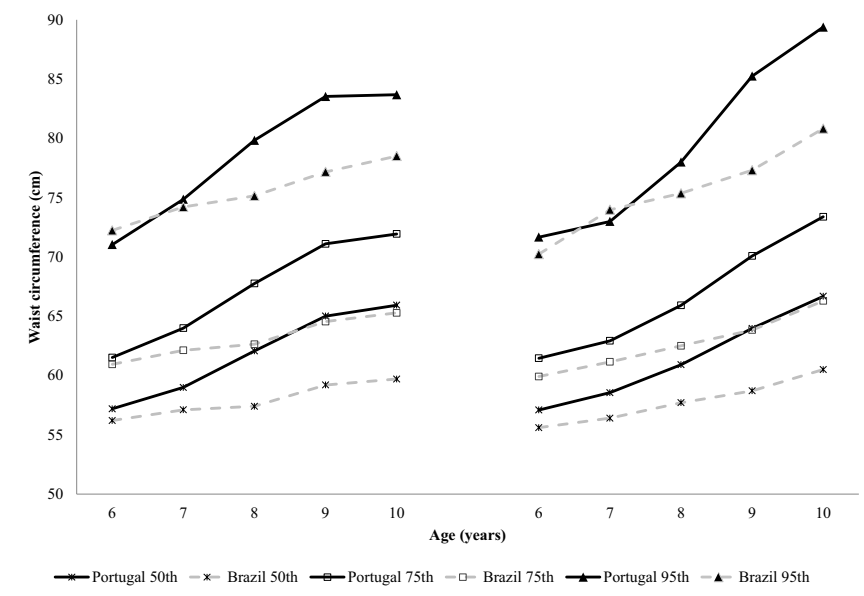

\section{Discussion}

This study presents the age and gender specific percentiles of 6-10-year-old children on WC designed for developed and developing countries. The main findings of this study are the new reference values for Portuguese and Brazilian children that establish percentile curves of normative parameters, according to national and international reference values. This data can be added to the existing international WC reference for children and comparisons can be made for national and international control in public health. Reference curves are an important tool to an early identification of possible risk of abdominal obesity in children and should be used in clinical practice and programs for weight control and obesity prevention.

To the best of our knowledge, no national reference curves have been published for 6-10-year-old Portuguese children using WC as recommended by WHO. There are reference curves published for Azorean adolescents (15-18 years) ${ }^{35}$, Portuguese children and adolescents (10-18years) in different benchmarks ${ }^{36}$, but no studies for children under 10 years old, which is filled by this study.

Portugal showed high WC percentile values, and several studies demonstrated that Portuguese obesity rates in children and adolescents are an important public health problem ${ }^{37-39}$. Furthermore, obesity was associated with several cardiovascular risk factors in Portuguese childre ${ }^{40}$. A Portuguese study comprising 1,433 children (6-12 yrs) highlighted that the overweight and obese prevalence was $22.3 \%$ and $10.7 \%$, respectively, and abdominal obesity prevalence (WC $\geq 90$ th) was $7.8 \%{ }^{41}$. Moreira et al. ${ }^{42}$ described the food pattern in 1,976 Portuguese children aged 5 - 10 years old and obese children presented a positive association with yoghurt, cheese, and ice cream intakes, which might be consumed as a part of the family's snacks or desserts, and the overweight/obese prevalence was $38.8 \%$ in girls and $38.6 \%$ in boys. A meta-analysis involving exclusively Portuguese children concluded that, in most studies, the higher prevalence of overweight/obesity was for boys compared to girls; the prevalence of overweight/obesity ranged from $19 \%$ to $35 \%$ and did not increase significantly in prevalence rates from 2002 to $2010^{38}$.

Since the last century, Brazil and other developing countries experience an epidemiological and nutritional transition characterized by a decrease in communicable diseases, malnutrition, and an increase in chronic diseases and obesity ${ }^{43,44}$. Significant changes in Brazilian food consumption patterns occurred between 2002 and 2008; there was a 30\% increase in the number of meals eaten out, $37.0 \%$ in the acquisition of readymade meals, $20.0 \%$ in soft drinks intake, while vegetable $(19.4 \%)$ and cereals $(20.5 \%)$ consumption decreased ${ }^{45}$. Data from the last Brazilian National Survey ${ }^{45,46}$ showed that since 1989-2009, 5-9-year-old children increased overweight prevalence from $15 \%$ to $34.8 \%$ and obesity increased from $4.1 \%$ to $16.6 \%$ among boys. Girls increased the overweight from $11.9 \%$ to $32 \%$ and obesity $2.4 \%$ to $11.8 \%$.

Previous studies associated WC with CVRF and metabolic syndrome in Brazilian children, and specific WC values could predict several cardiometabolic risks ${ }^{7,47,48}$. Rocco et al. ${ }^{48}$ suggested WC cutoff values to detect a cluster of CVRF ( $\mathrm{WC}=80.5 \mathrm{~cm}$ for boys; $\mathrm{WC}=83.0 \mathrm{~cm}$ for girls) in Brazilian children and adolescents. Obesity in Brazilian children was associated with the duration of the breast-feeding period, the legal guardian's weight excess, sedentarism, physical activity level, and rapid chewing ${ }^{49}$.

Obesity seems to have a different behavior in developed and developing countries. In developing countries, especially in Latin America, the overweight in preschoolers was associated with the area of residence, the high level of maternal education, and the female $\operatorname{sex}^{50}$, and the authors speculate that overweight may become a greater problem in a higher number of countries in school-age children. Studies have found significant differences in obesity prevalence among European children from the East $(6.5 \%)$ and West (1.6\%) regions, being associated to boys, low maternal education level, younger parents, and children living in developing countries (Upper Middle Income) such as Romania or Bulgaria ${ }^{4}$.

Brazilian and Portuguese municipalities presented similar rates of overweight and obesity; however, there was a signicant difference revelead by ANCOVA for WC values. Portugal had the highest WC values for all ages, regardless of sex, compared to Brazil and higher WC $>75$ th frequency. In addition to the differences in nutritional transition, it is worth to highlight that physical activity (PA) have been considered a factor associated with central obesity in children ${ }^{51}$.

The Global Alliance of Healthy and Active Children organized reports on children's and young people's physical activity (PA) from 38 countries, representing $60 \%$ of the world's population. Low-income countries generally had better scores on global physical activity compared to higher-income countries ${ }^{52}$. The 2016 Brazilian Physical Activity Report Card $^{53}$ shows that, overall, PA levels are low among Brazilian children and young people (grade "C"). The cards estimated that $41.7 \%$ of $6-19$-yearold Brazilians meet the PA guidelines ( $\geq 300$ minutes/week). The results for Portuguese children ${ }^{54}$ conclude that they did not achieve enough PA levels according to the recommendations (grade "D"). Physical activity levels in both countries are similar 
and insufficient to meet the recommendation for children. There is need to promote PA practice in the young population from both countries.

After comparing the data from developed countries, one country considered as "developing" and recently classified as "developed" showed the highest WC values. If Chile had not entered the group of developed countries, Portugal would have shown the highest WC percentile values. This data might suggest that countries that have experienced economic growth (from Middle to High Income) have a late epidemiological and nutritional transition. Gomez-Campos et al. ${ }^{25}$ have showed significant differences between CDC-2012 references and Chilean children. Chilean 6-9-year-old boys showed a higher WC when compared to American children (CDC, 2012, $p<0.05$ ); WC values were similar between Chilean girls and CDC-2012 reference values in females aged 6-12, but this WC comparison was measured with a different benchmark. When these authors ${ }^{25}$ compared Chilean WC to Malaysian and Bulgarian children, Chilean children had the highest values for the 50th percentile compared to other international references for both sexes and the same WC benchmark. Regardless of the methodology, it is expected that children from different ethnic groups have different growth and development patterns.

Nawarycz et al. ${ }^{55}$ compared WC distributions between children from Poland and Germany; WC values in German boys and girls were significantly higher compared to Polish children, and the authors pointed out the need for a consensus on WC measurements and suggested the benchmark recommended by WHO.

Bustamante et al. ${ }^{17}$ compared WC reference values of Peruvian children with other international references. The WC Peruvian children values (4-17 yrs) were lower than the ones for North-Americans and Argentinean children of all ages. They have found that WC differences between Peruvian and NorthAmerican children were of $\sim 5.4 \mathrm{~cm}$ in boys and $\sim 6.6 \mathrm{~cm}$ in girls, while for Peruvian and Argentinean children were it was of $\sim 2.8 \mathrm{~cm}$ in boys and $\sim 3.9 \mathrm{~cm}$ in girls aged between 6 and 13 . However, the found differences can be partly explained by the use of different benchmarks to measure WC; however, it is not recommended to compare different WC measurement points.

This study has several limitations and strengths. Data were representative for both municipalities/regions, but not for both countries. Variations in the data collection period were found in the different municipalities (Brazil: 2009-2011, and Portugal: 2009-2015) because of logistical problems and partnerships. Researchers should be aware of the importance of WC comparisons using different benchmarks. In this study, we limited the comparisons to studies that used the same benchmark and LMS methodology. This research presented the age and gender specific percentiles of 6-10-year-old children WC designs for developed and developing countries. Moreover, we presented new reference values for Portuguese and Brazilian children, thus establishing percentile curves with normative parameters according to the national and international references. We believe future research need to compare the reference values and more accurate methods of body composition measurement and prediction cardiovascular risk factors.

\section{Conclusion}

This study has designed new WC reference values for Portuguese and Brazilian children. Reference percentile curves are an important tool when assessing abdominal obesity or central obesity in children. This data might be used on clinical practice and on national or international comparison.

A serious public health problem among Portuguese and Brazilian children could be prevented with efforts regarding this age group. Special attention should be given to Portuguese children, considering they have shown high WC values compared to other countries.

\section{References}

1. Zukiewicz-Sobczak W, Wroblewska P, Zwolinski J, ChmielewskaBadora J, Adamczuk P, Krasowska E, et al. Obesity and poverty paradox in developed countries. Ann Agric Environ Med. 2014;21(3):590-4.

2. Misra A, Bhardwaj S. Obesity and the metabolic syndrome in developing countries: focus on South Asians. Nestle Nutr Inst Workshop Ser. 2014;78:133-40.

3. Bhurosy T, Jeewon R. Overweight and obesity epidemic in developing countries: a problem with diet, physical activity, or socioeconomic status? ScientificWorldJournal. 2014;2014:964236.

4. Olaya B, Moneta MV, Pez O, Bitfoi A, Carta MG, Eke C, et al. Country-level and individual correlates of overweight and obesity among primary school children: a cross-sectional study in seven European countries. BMC Public Health. 2015;15:475.

5. Wabitsch M, Moss A, Kromeyer-Hauschild K. Unexpected plateauing of childhood obesity rates in developed countries. BMC Med. 2014;12:17.

6. Kelishadi R, Mirmoghtadaee P, Najafi H, Keikha M. Systematic review on the association of abdominal obesity in children and adolescents with cardio-metabolic risk factors. J Res Med Sci. 2015;20(3):294-307.

7. Andaki AC, Tinoco AL, Mendes EL, Andaki Junior R, Hills AP, Amorim PR. Different waist circumference measurements and prediction of cardiovascular risk factors and metabolic syndrome in children. Obes Res Clin Pract. 2012;6(2):e91-e174.

8. Dong B, Wang Z, Yang Y, Wang HJ, Ma J. Intensified association between waist circumference and hypertension in abdominally overweight children. Obes Res Clin Pract. 2016;10(1):24-32.

9. Aylanc H, Aylanc N, Yildirim S, Tekin M, Battal F, Kaymaz $\mathrm{N}$, et al. Relationship between Abdominal Aortic Intima Media Thickness and Central Obesity in Children. Horm Res Paediatr. 2016;85(1):43-8.

10. Moschonis G, Karatzi K, Polychronopoulou MC, Manios Y. Waist circumference, trunk and visceral fat cutoff values for detecting hyperinsulinemia and insulin resistance in children: the Healthy Growth Study. Eur J Nutr. 2016;55(7):2331-4.

11. Mehta SK, Richards N, Lorber R, Rosenthal GL.Abdominal obesity, waist circumference, body mass index, and echocardiographic measures in children and adolescents. Congenit Heart Dis. 2009;4(5):338-47. 
12. Fredriks AM, van Buuren S, Fekkes M, Verloove-Vanhorick SP, Wit JM. Are age references for waist circumference, hip circumference and waist-hip ratio in Dutch children useful in clinical practice? Eur J Pediatr. 2005;164(4):216-22.

13. Schwandt P, Kelishadi R, Haas GM. First reference curves of waist circumference for German children in comparison to international values: the PEP Family Heart Study. World J Pediatr. 2008;4(4):259-66.

14. Wohlfahrt-Veje C, Tinggaard J, Winther K, Mouritsen A, Hagen CP, Mieritz MG, et al. Body fat throughout childhood in 2647 healthy Danish children: agreement of BMI, waist circumference, skinfolds with dual X-ray absorptiometry. Eur J Clin Nutr. 2014;68(6):664-70.

15. Hatipoglu N, Ozturk A, Mazicioglu MM, Kurtoglu S, Seyhan S, Lokoglu F. Waist circumference percentiles for 7- to 17-year-old Turkish children and adolescents. Eur J Pediatr. 2008;167(4):383-9.

16. Bacopoulou F, Efthymiou V, Landis G, Rentoumis A, Chrousos GP. Waist circumference, waist-to-hip ratio and waist-to-height ratio reference percentiles for abdominal obesity among Greek adolescents. BMC Pediatr. 2015;15:50.

17. Bustamante A, Freitas D, Pan H, Katzmarzyk PT, Maia J. Centile curves and reference values for height, body mass, body mass index and waist circumference of Peruvian children and adolescents. Int J Environ Res Public Health. 2015;12(3):2905-22.

18. Rerksuppaphol S, Rerksuppaphol L. Waist Circumference, Waistto-Height Ratio and Body Mass Index of Thai Children: Secular Changes and Updated Reference Standards. J Clin Diagn Res. 2014;8(11):PC05-9.

19. Freedman DS, Kit BK, Ford ES. Are the Recent Secular Increases in Waist Circumference among Children and Adolescents Independent of Changes in BMI? PLoS One. 2015;10(10):e0141056.

20. Anzo M, Inokuchi M, Matsuo N, Takayama JI, Hasegawa T. Waist circumference centiles by age and sex for Japanese children based on the 1978-1981 cross-sectional national survey data. Ann Hum Biol. 2015;42(1):56-61.

21. Garnett SP, Baur LA, Cowell CT. The prevalence of increased central adiposity in Australian school children 1985 to 2007. Obes Rev. 2011;12(11):887-96.

22. World Health Organization. Physical status: the use and interpretation of anthropometry. Report of a WHO Expert Committee. World Health Organ Tech Rep Ser. 1995;854:1-452.

23. Cole TJ, Bellizzi MC, Flegal KM, Dietz WH. Establishing a standard definition for child overweight and obesity worldwide: international survey. BMJ. 2000;320(7244):1240-3.

24. World Health Organization. Obesity: preventing and managing the global epidemic. Report of a WHO consultation. World Health Organ Tech Rep Ser. 2000;894:i-xii, 1-253.

25. Gomez-Campos R, Andruske CL, Hespanhol J, Torres JS, Arruda M, Luarte-Rocha C, et al. Waist Circumferences of Chilean Students: Comparison of the CDC-2012 Standard and Proposed Percentile Curves. Int J Environ Res Public Health. 2015;12(7):7712-24.

26. Mederico M, Paoli M, Zerpa Y, Briceno Y, Gomez-Perez R, Martinez JL, et al. Reference values of waist circumference and waist/hip ratio in children and adolescents of Merida, Venezuela: comparison with international references. Endocrinol Nutr. 2013;60(5):235-42.

27. Jackson RT, Al Hamad N, Prakash P, Al Somaie M. Waist circumference percentiles for Kuwaiti children and adolescents. Public Health Nutr. 2011;14(1):70-6.

28. Nawarycz LO, Krzyzaniak A, Stawinska-Witoszynska B, Krzywinska-Wiewiorowska M, Szilagyi-Pagowska I, Kowalska $\mathrm{M}$, et al. Percentile distributions of waist circumference for 7-19-year-old Polish children and adolescents. Obes Rev. 2010;11(4):281-8.

29. Galcheva SV, Iotova VM, Yotov YT, Grozdeva KP, Stratev VK, Tzaneva VI. Waist circumference percentile curves for Bulgarian children and adolescents aged 6-18 years. Int J Pediatr Obes. 2009;4(4):381-8.

30. Ying-Xiu Z, Ya-Lin L, Jin-Shan Z, Zun-Hua C, Jing-Yang Z. Distributions of waist circumference and waist-to-height ratio for children and adolescents in Shandong, China. Eur J Pediatr. 2013;172(2):185-91.

31. Poh BK, Jannah AN, Chong LK, Ruzita AT, Ismail MN, McCarthy D. Waist circumference percentile curves for Malaysian children and adolescents aged 6.0-16.9 years. Int J Pediatr Obes. 2011;6(3-4):229-35.

32. Cohen J. A power primer. Psychol Bull. 1992;112(1):155-9.

33. Cole TJ, Green PJ. Smoothing reference centile curves: the LMS method and penalized likelihood. Stat Med. 1992;11(10):1305-19.

34. Cole TJ, Freeman JV, Preece MA. British 1990 growth reference centiles for weight, height, body mass index and head circumference fitted by maximum penalized likelihood. Stat Med. 1998;17(4):407-29.

35. Santos R, Moreira C, Ruiz JR, Vale S, Soares-Miranda L, Moreira $\mathrm{P}$, et al. Reference curves for BMI, waist circumference and waistto-height ratio for Azorean adolescents (Portugal). Public Health Nutr. 2012;15(1):13-9.

36. Sardinha LB, Santos R, Vale S, Coelho e Silva MJ, Raimundo AM, Moreira H, et al. Waist circumference percentiles for Portuguese children and adolescents aged 10 to 18 years. Eur J Pediatr. 2012;171(3):499-505.

37. Sardinha LB, Santos R, Vale S, Silva AM, Ferreira JP, Raimundo AM, et al. Prevalence of overweight and obesity among Portuguese youth: a study in a representative sample of 10-18-year-old children and adolescents. Int J Pediatr Obes. 2011;6(2-2):e124-8.

38. Gomes TN, Katzmarzyk PT, dos Santos FK, Souza M, Pereira S, Maia JA. Overweight and obesity in Portuguese children: prevalence and correlates. Int J Environ Res Public Health. 2014;11(11):11398-417.

39. Padez C, Mourao I, Moreira P, Rosado V. Prevalence and risk factors for overweight and obesity in Portuguese children. Acta Paediatr. 2005;94(11):1550-7.

40. Pedrosa C, Oliveira BM, Albuquerque I, Simoes-Pereira C, Vazde-Almeida MD, Correia F. Obesity and metabolic syndrome in 7-9 years-old Portuguese schoolchildren. Diabetol Metab Syndr. 2010;2(1):40.

41. Albuquerque D, Nobrega C, Samouda H, Manco L. Assessment of obesity and abdominal obesity among Portuguese children. Acta Med Port. 2012;25(3):169-73.

42. Moreira P, Santos S, Padrao P, Cordeiro T, Bessa M, Valente H, et al. Food patterns according to sociodemographics, physical 
activity, sleeping and obesity in Portuguese children. Int J Environ Res Public Health. 2010;7(3):1121-38.

43. Kain J, Vio F, Albala C. Obesity trends and determinant factors in Latin America. Cad Saude Publica. 2003;19 Suppl 1:S77-86.

44. Uauy R, Albala C, Kain J. Obesity trends in Latin America: transiting from under- to overweight. J Nutr. 2001;131(3):893S-9S.

45. IBGE. Pesquisa de Orçamentos Familiares 2008-2009. Avaliação Nutricional da Disponibilidade Domiciliar de Alimentos no Brasil. In: Ministério do Planejamento OeG, editor. Rio de Janeiro.2010.

46. IBGE. Pesquisa de Orçamentos Familiares 2008-2009: antropometria e estado nutricional de crianças adolescentes e adultos no Brasil. In: Ministério do Planejamento OeG, editor. Rio de Janeiro.2010.

47. Andaki AC, Tinoco AL, Mendes EL, Andaki Junior R, Hills AP, Amorim PR. Anthropometry and physical activity level in the prediction of metabolic syndrome in children. Public Health Nutr. 2014;17(10):2287-94.

48. Rocco ER, Mory DB, Bergamin CS, Valente F, Miranda VL, Calegare BF, et al. Optimal cutoff points for body mass index, waist circumference and HOMA-IR to identify a cluster of cardiometabolic abnormalities in normal glucose-tolerant Brazilian children and adolescents. Arq Bras Endocrinol Metabol. 2011;55(8):638-45.

49. Honorio RF, Costa Monteiro Hadler MC. Factors associated with obesity in brazilian children enrolled in the school health program: a case-control study. Nutr Hosp. 2014;30(3):526-34.

50. Martorell R, Kettel Khan L, Hughes ML, Grummer-Strawn LM. Overweight and obesity in preschool children from developing countries. Int J Obes Relat Metab Disord. 2000;24(8):959-67.

51. Qiao Y, Zhang T, Liu H, Katzmarzyk PT, Chaput JP, Fogelholm $\mathrm{M}$, et al. Joint association of birth weight and physical activity/ sedentary behavior with obesity in children ages 9-11 years from 12 countries. Obesity (Silver Spring). 2017;25(6):1091-7.

52. Tremblay MS, Barnes JD, Gonzalez SA, Katzmarzyk PT, Onywera VO, Reilly JJ, et al. Global Matrix 2.0: Report Card Grades on the Physical Activity of Children and Youth Comparing 38 Countries. J Phys Act Health. 2016;13(11 Suppl 2):S343-S66.
53. Nardo N, Jr., Silva DA, de Moraes Ferrari GL, Petroski EL, Pacheco RL, Martins PC, et al. Results From Brazil's 2016 Report Card on Physical Activity for Children and Youth. J Phys Act Health. 2016;13(11 Suppl 2):S104-s9.

54. Mota J, MJ ES, Raimundo AM, Sardinha LB. Results From Portugal's 2016 Report Card on Physical Activity for Children and Youth. J Phys Act Health. 2016;13(11 Suppl 2):S242-S5.

55. Nawarycz T, Haas GM, Krzyzaniak A, Schwandt P, OstrowskaNawarycz L. Waist Circumference and Waist-to-Height Ratio Distributions in Polish and German Schoolchildren: Comparative Analysis. Int J Prev Med. 2013;4(7):786-96.

\section{Acknowledgements}

Financial Support: This study was partially supported by FAPEMIG - Fundação de Amparo a Pesquisa do Estado de Minas Gerais (CDS - APQ-02279-11).

The authors AA (Grant number 208184/2014-7) and AS (Grant number 6099-13-0) thank the Conselho Nacional de Pesquisa CNPQ and the Brazilian Government Scholarship Program Ciencia sem Fronteiras.

The authors thank the children for their participation in the study, as well as their parents for their cooperation.

\section{Corresponding author}

Alynne Andaki

Department of Sport Sciences, Universidade Federal do Triângulo Mineiro. Avenida Getúlio Guaritá, $n^{\circ} 159,3^{\circ}$ andar. Centro Educacional da UFTM，Bairro: Nossa Senhora da Abadia. CEP: 38025-440 Uberaba, /MG, Brazil.

Email: alynneandaki@yahoo.com.br; alynne.andaki@uftm.edu.br

Manuscript received on March 15, 2017

Manuscript accepted on June 25, 2017

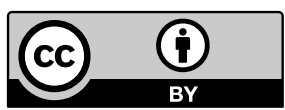

Motriz. The Journal of Physical Education. UNESP. Rio Claro, SP, Brazil - eISSN: 1980-6574 - under a license Creative Commons - Version 3.0 